\title{
Proposal for Use of Indoor Cells for Supply Electronic Loads Remotely
}

\author{
Dyego de Campos, Bryan D. Pinheiro, Diego L. da Silva, and Clovis A. Petry
}

\begin{abstract}
This work presents the development of a indoors capitation processing storage circuit of light energy for. To begin, it describing the components of the project, such as photovoltaic panels for indoor, dc-dc converter and super capacitors. Then, propose a low power and high performance processing energy circuit, associate a new energy storage technology. As well as, realized a comparative study of different thin film photovoltaic cells under different lighting characteristics. The laboratory prototype was implemented to verify the proposed system functionality containing a panel of 7 $\mathrm{V} \times 1 \mathrm{~mA}$, associated super capacitors $6 \mathrm{~F} \times 11 \mathrm{~V}$ to feed variable current presence sensor of $18 \mathrm{uA}$ at $4.5 \mathrm{~mA}$ and $9 \mathrm{~V}$.
\end{abstract}

Index Terms-Indoor cell, photovoltaic energy, supercapacitores.

\section{INTRODUCTION}

Currently, the number of portable electronic equipment has increased; especially those that are not connected to the electric network. Besides that, the demand for energy storage devices is increasing. These normally are batteries, and more recently super capacitors. Usually the battery materials are made of heavy metals, generating disposal problems and can be harmful to the environment, if it is not done correctly [1].

The use of equipments where access to mains power is not available, it is possible through the photovoltaic devices, which convert solar energy into electrical energy [2]. The most commonly used cells elements are the crystalline silicon but indoors it is not viable due your large volume and low efficiency under artificial radiation. Then, a thin film device is a possible solution, because it has lower cost, using less material. Moreover, the cells are made with flexible substrates, transparent, light and have a more attractive aesthetic, making it possible indoors use [3], [4].

This way, the idea of this work is to reuse the artificial or natural light energy captured by thin films modules [5]. This one going to use super capacitor to store the energy and use in periods where there is no ambient lighting. This way, this circuit will replacing the traditional alkaline battery with $9 \mathrm{~V}$ and about $250 \mathrm{~mA}$, or electric network how means of direct energy source or recharge [6]-[8].

The structure of this article is divided into topics. Section II shows the methodology used; Section III and Section IV respectively, photovoltaic devices and super capacitors; the proposed structure is presented in Section V; in Section VI is

Manuscript received April 20, 2015; revised August 27, 2015. This work was supported in part by the Federal Institute of Science and Technology of Santa Catarina (IFSC) and by National Council for Scientific and Technological Development (CNPq).

The authors are with the Federal Institute of Science and Technology of Santa Catarina, Florianopolis, SC, Brazil (e-mail: \{dyego.campos, petry\}@ifsc.edu.br, \{bryandouglaspinheiro, maskx1\}@gmail.com). carried out a comparative study of thin film cells; already Section VII there is an application example of the framework; the design of the structure is shown in Section VIII; in turn, Section IX presents the results obtained with the work. Finally, in Section X, are presented the findings of the work done.

\section{Methodology}

First of all, it was carried out a study of the subject and the technologies used in the project such as photovoltaics cells and available energy storage devices. Soon after, the components and technologies used were chosen. Then, the components were submitted the individual tests, such as: load, photovoltaic cells, and super capacitors. These practical results were compared with theory. In parallel to that described, the documentation of each step was carried out with the purpose of generating content for later playback and with the intention to gain mastery over the technologies presented. It was also carried out a comparative study between cells from different manufacturers submitted to different lighting conditions.

\section{Photovoltaic Devices Technologies}

Cells or photovoltaic devices [3] can be divided into three groups, it is according to their technology and market application. This way, those which are manufactured using crystalline silicon, both monocrystalline silicon (m-Si) as polycrystalline ( $\mathrm{p}-\mathrm{Si}$ ); and those that are made from thin films of amorphous silicon (a-Si), cadmium telluride (CdTe), or copper indium diselenide / gallium (CIS / CIGS).

Thin film cells use a smaller amount of material in relation to the crystalline silicon cell, its manufacturing process and substrates used are less expensive. These may be made of flexible materials, lightweight and transparent [9], [10].

The type of module is based on the Table I [3], this is made one cost-benefit analysis based on some data: material costs, manufacturing processes, and operating efficiency of energy conversion. So, it was opted for the a-Si for the best cost-benefit ratio, and present a better spectral response in relation to the $\mathrm{c}-\mathrm{Si}$, for example.

TABLE I: COST $\times$ BENEFIT RELATION OF THE PHOTOVOLTAICS MODULES

\begin{tabular}{|c|c|}
\hline Material & Cost $\times$ Benefit \\
\hline Polycrystalline silicon $(\mathrm{pc}-\mathrm{Si})$ & 3.5 \\
\hline Monocrystalline silicon $(\mathrm{mc}-\mathrm{Si})$ & 2.3 \\
\hline Amorphous silicon $(\mathrm{a}-\mathrm{Si})$ & 1.5 \\
\hline Cadmium telluride $(\mathrm{CdTe})$ & 0.42 \\
\hline Copper Indium diselenide (CIS) & 0.29 \\
\hline
\end{tabular}

The group used in this work will be to thin films and the 
photovoltaic module used, Fig. 1, will be the type of amorphous silicon, model 07/096/096COA the SOLEMS SA manufacturer.

The module features 07/096/096COA, according to manufacturer's datasheet are shown in Table II.

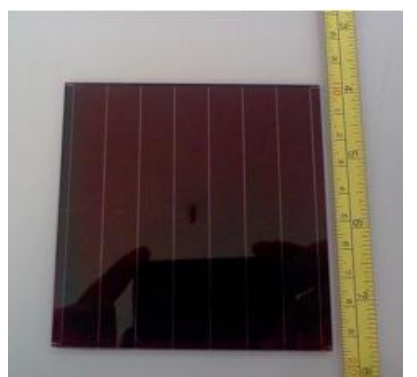

Fig. 1. Photovoltaic module.

TABLE II: MODULE ELECTRICAL CHARACTERISTICS 07/096/096COA

\begin{tabular}{|c|c|c|c|c|}
\hline \multicolumn{2}{|c|}{ Environment } & $\begin{array}{c}\text { Voc } \\
{[\mathrm{V}]}\end{array}$ & $\begin{array}{c}\text { Icc } \\
{[\mu \mathrm{A}]}\end{array}$ & $\begin{array}{c}\mathrm{MPP} \\
\mathrm{I} / \mathrm{V} \\
{[\mu \mathrm{A} / \mathrm{V}]}\end{array}$ \\
\hline \multirow{2}{*}{ Indoor } & $200 \operatorname{lux}$ & 3.9 & 160 & $133 / 2.8$ \\
\cline { 2 - 5 } & $1000 \mathrm{lux}$ & 4.2 & 820 & $660 / 3$ \\
\hline Outdoor $\left(25^{\circ}-\mathrm{AM} 1,5\right)$ & $200 \mathrm{~W} / \mathrm{m} 2$ & 4.5 & 20000 & $0.17 / 3.5$ \\
\cline { 2 - 5 } & $1000 \mathrm{~W} / \mathrm{m} 2$ & 5 & 99000 & $0.65 / 3.7$ \\
\hline
\end{tabular}

\section{ENERGy StORAGE TECHNOLOGY}

Energy storage devices used more frequently nowadays are conventional capacitors, batteries and supercapacitors.

Conventional capacitor is formed by two separated metallic plates by an dielectric insulating material. The capacitance depends on the plates surfaces and the dielectric material thickness which it is made.

So that [6], supercapacitors, also known as ultra capacitors or electric double layer capacitor (EDLC), these are condenser of energy that have a good power density when compared to other condensers, most used batteries and conventional capacitors. Supercapacitor according to [11], it has a big surface area and do not has the solid dielectric as the capacitors. According to [12], this is achieved by using a carbon-based porous electrode that is immersed in a conductive material, called electrolyte, which penetrates into the carbon pores and form ultra thin film called dielectric, by reaction, which covers all pores.

The supercapacitor used in this work, Fig. 2, is the EDLSG155V5R5C Cornell Dubilier the manufacturer. The supercapacitor characteristics used are shown in Table III.

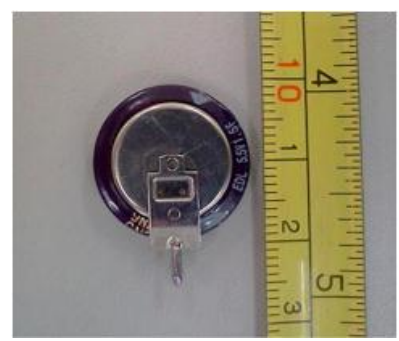

Fig. 2. Applied supercapacitor.

TABLE III: SUPERCAPACITOR EDLSG155V5R5C CHARACTERISTICS

\begin{tabular}{|c|c|}
\hline Capacitance & $1.5 \mathrm{~F}$ \\
\hline Nominal voltage & $5.5 \mathrm{~V}$ \\
\hline Series equivalent resistance (RSE) & $30 \Omega$ \\
\hline Temperature range & $-25^{\circ} \mathrm{C}$ até $85^{\circ} \mathrm{C}$ \\
\hline
\end{tabular}

According to [1], [13], the batteries behave as portable power plants that transform chemical energy into electrical energy. They can be divided, such as, primary (disposable) and secondary (rechargeable). The kind of batteries most common household are alkaline and zinc carbon, primary type, and nickel-cadmium batteries, secondary type. Alkaline batteries are not composed by mercury currently. While zinc-carbon have low mercury content. However, batteries may contain heavy metals in their composition in addition to mercury, such as lead, zinc and cadmium. The big problem with these storage devices is the incorrectly discard. It can end causing environmental and health problems to humans, especially for unregulated devices, fakes, which may contain heavy metals levels above those permitted.

The Table IV [6] shows a comparison between the three storage devices used nowadays.

TABLE IV: COMPARISON BETWEEN STORAGE DEVICES

\begin{tabular}{|c|c|c|c|}
\hline Characteristic & $\begin{array}{c}\text { Conventional } \\
\text { Capacitor }\end{array}$ & EDLC & Batteries \\
\hline $\begin{array}{c}\text { Energy density } \\
{[\mathrm{Wh} / \mathrm{kg}]}\end{array}$ & 0.1 & 3 & 100 \\
\hline $\begin{array}{c}\text { Power density } \\
{[\mathrm{W} / \mathrm{Kg}]}\end{array}$ & $10^{7}$ & 3,000 & 100 \\
\hline Charge time [s] & $10^{3}-10^{6}$ & $0.3-30$ & $>1,000$ \\
\hline Discharge time [s] & $10^{3}-10^{6}$ & $0.3-30$ & $1,000-10,000$ \\
\hline Cycles number & $10^{10}$ & $10^{6}$ & 1,000 \\
\hline Durability [years] & 30 & 30 & 5 \\
\hline Efficiency [\%] & $>95$ & $85-98$ & $70-85$ \\
\hline
\end{tabular}

\section{PROPOSAL SYSTEM}

Fig. 3 is the project overview. This one is consists of a photovoltaic panel, which captures the artificial or natural light energy from the environment and convert it into electricity. Then, it is used the converter to raise the panel voltage, as a result of the load operating voltage. After passing through the energy converter, it is held in storage by supercapacitors to be use by load, for example, a presence sensor.

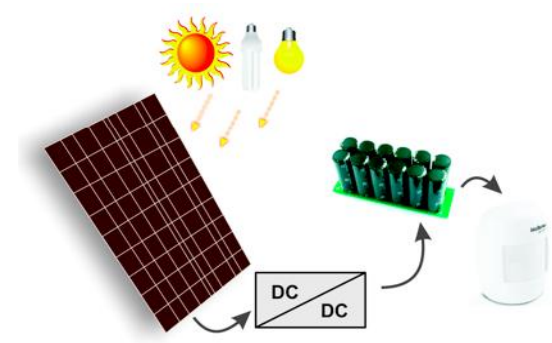

Fig. 3. Proposed system.

\section{COMPARATIVE STUdy BETWEEN DIFFERENT FINE FILM PV CELLS}

The cells chosen for study are from China Solar and SOLEMS manufacturers and, as shown in Fig. 4 and Fig. 5.

The following was built dark chamber (Fig. 6) as a way to control the brightness of the experiments at 200 lx. This value was chose so that all environments with less brightness are considered dark.

A Luxmeter was used as tool for measuring light brightness. The exact value of luminosity was reached with a 
electric cable where the lamp was positioned in the right height. The lamps used are shown in Fig. 7.

During the experiments, the current and voltage measurements were taken through two multimeters, where one is precision (Fig. 8).

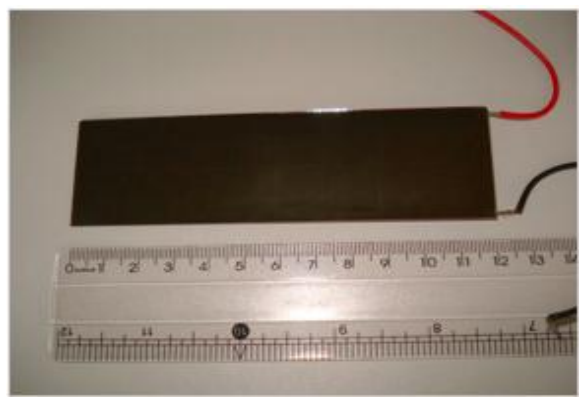

Fig. 4. China Solar photovoltaic cell.

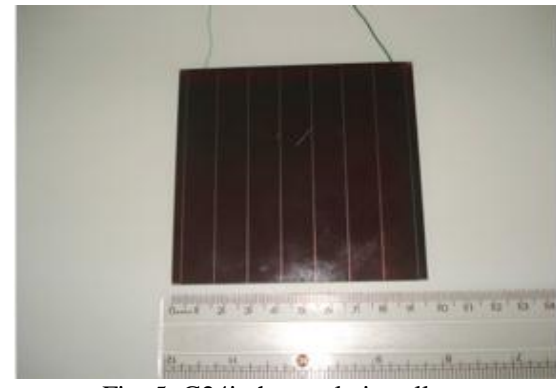

Fig. 5. G24i photovoltaic cell.

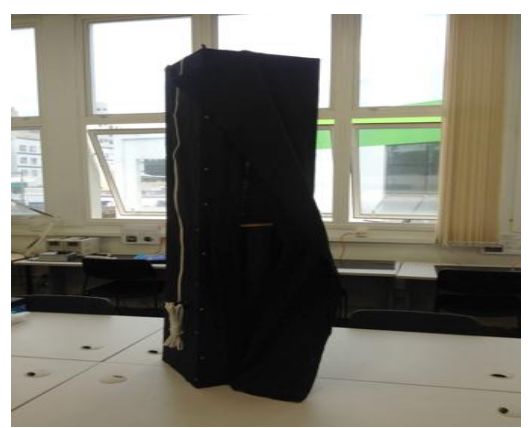

Fig. 6. Dark chamber.

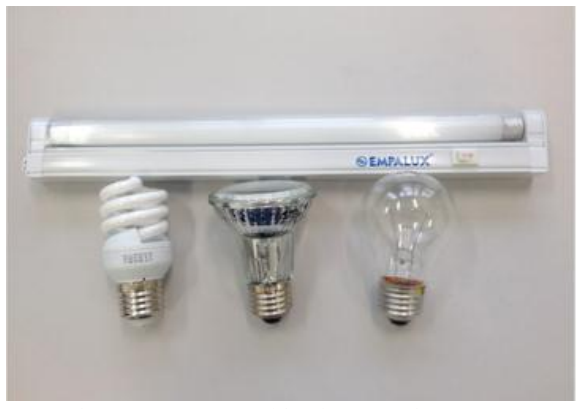

Fig. 7. Lamps used in the experiment.

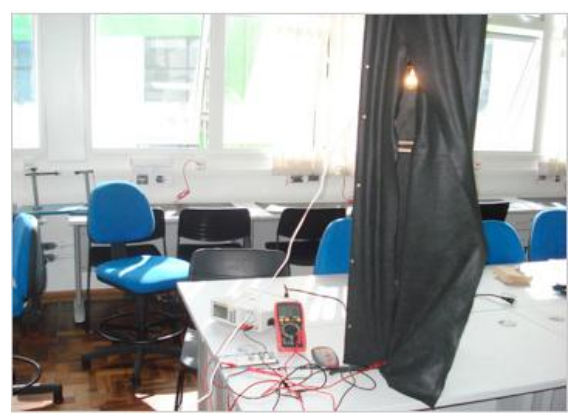

Fig. 8. Equipment used in the experiment.
By measurements at assay, it was observed that incandescent lamps, even though, a more rudimentary technology, which has been transferred best energy for the cell. And other technologies of the lamps, how much newest technology, the worse the energy transfer to the cell.

This way, the data to building graphics were acquired through the experiments. These can show better the result from assay, as Fig. 9 and Fig. 10 explains.

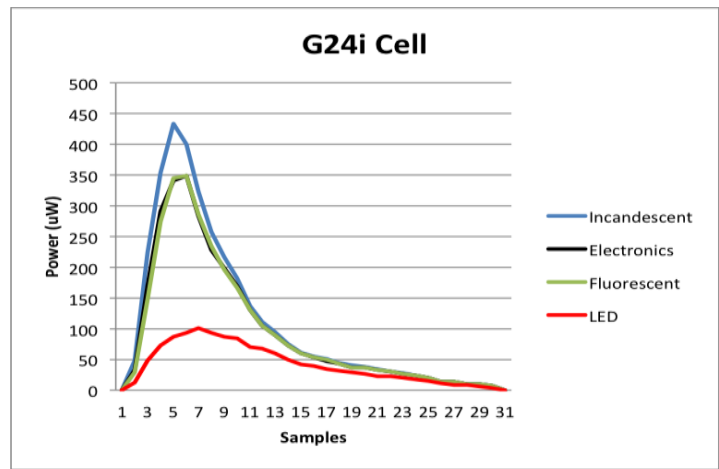

Fig. 9. Comparative graph of energy measurements generated by the cell, manufacturer $\mathrm{G} 24 \mathrm{i}$.

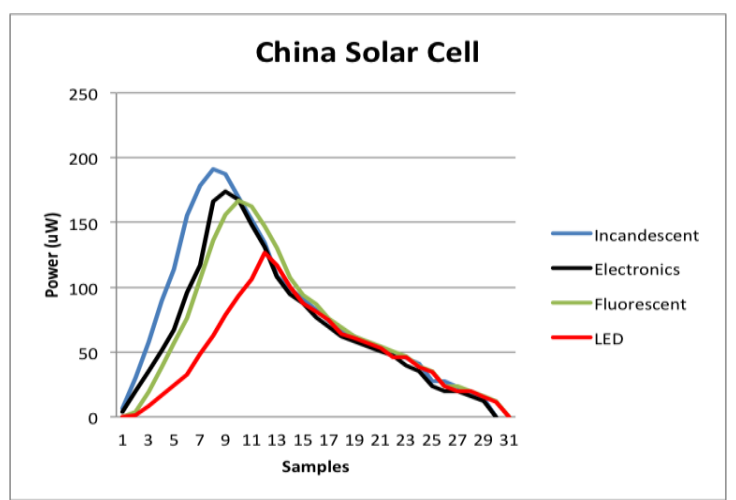

Fig. 10. Comparative graph of energy measurements generated by the cell, manufacturer China Solar.

This power generation behavior can be observed in all measures cells. Even if they are from different manufacturers as well as their technology.

The results observed at Fig. 9 and Fig. 10 indicate that incandescent lamps are light sources that allow better performance in power generation of indoor cells. This occurs by this lamps have light wavelength, close to light emitted by sun; while economic bulbs (electronics and fluorescent) and LED emit light with different wavelengths of the wavelength of the light emitted by the sun. Because cause it, the cell yield is lower.

\section{SySTEM APPLICATION EXAMPLE}

As implementation of the project is of low-power, a indoor charge is required, preferably a product of regional companies. Thus, the model IVP2000SF wireless presence sensor, Intelbras manufacturer, was chosen.

The objective of this project is to replace the battery and use as a power source of the presence sensor (charge) photovoltaic panel and supercapacitors. So, the period in which the environment is illuminated, the supercapacitors are feed by panel, which aims to power the load, including periods without ambient lighting. 
Based on manufacturer information and product testing, the sensor data that were obtained are presented in Table V. The sensor has three operating modes: Initial, testing and normal. The initial mode is for auto-configuration sensor. The test mode the user has the purpose of performing the sensor testing, for example, coverage angle adjustment. Already normal mode, it is the normal operating mode of the sensor.

TABLE V: SENSOR CONSUMPTION

\begin{tabular}{|c|c|c|c|c|}
\hline \multicolumn{2}{|c|}{ Mode } & Time $[\mathrm{s}]$ & $\mathrm{I}[\mathrm{mA}]$ & $\mathrm{I}_{\text {average }}[\mathrm{mA}]$ \\
\hline Initial & Added & 20 & 0,78 & 0,78 \\
\hline \multirow{2}{*}{ Test } & Added & 3 & 5,12 & 2 \\
\cline { 2 - 4 } & On hold & 3 & 0.0178 & \\
\hline \multirow{2}{*}{ Normal } & Added & 3 & 5,12 & \multirow{2}{*}{0,182} \\
\cline { 2 - 4 } & On hold & 90 & 0.0178 & \\
\hline
\end{tabular}

\section{DESIGN OF THE PROPOSAL SYSTEM}

Energy can be calculated by Eq. (1):

$$
E=P \times t
$$

$E$ - Energy in Joule [J];

$P$ - Power in Watts [W];

$t$ - Time in seconds [s].

According the manufacture manual, the sensor operate voltage can varies between 7 and $9 \mathrm{~V}$. So, it was chosen $7 \mathrm{~V}$.

Eq. (2) is the energy demanded of the sensor during its Initial mode. In Eq. (3) have the energy required for the test mode. And for the normal mode, considering the acting sensor for $24 \mathrm{~h}$, the energy required is in Eq. (4).

$$
\begin{gathered}
E_{\text {initial mode }}=0.78 \mathrm{~mA} \times 7 \times 20 \\
E_{\text {initial mode }}=0.109 \mathrm{~J} \\
E_{\text {test mode }}=2.56 \mathrm{~mA} \times 7 \times 600 \\
E_{\text {test mode }}=10.75 \mathrm{~J} \\
E_{\text {normal mode }}=0.182 \mathrm{~mA} \times 7 \times 86400 \\
E_{\text {normal mode }}=110.07 \mathrm{~J}
\end{gathered}
$$

With the chosen load, and energy values demanded by the load, the next step is to calculate the number of modules and type of arrangement, that these modules need, for the energy supply. The most critical case is the normal mode. Which the sensor uses more energy.

For the tests were used 4 modules, due to the price to acquire a larger number of these. The modules are interconnected to form a panel, Fig. 11. The electrical characteristics of the panel are shown in Fig. 12. The curves were simulated by approximations by straight. The maximum power point (MPP) is for a voltage of $5.6 \mathrm{~V}$ and a current of $264 \mathrm{uA}$.

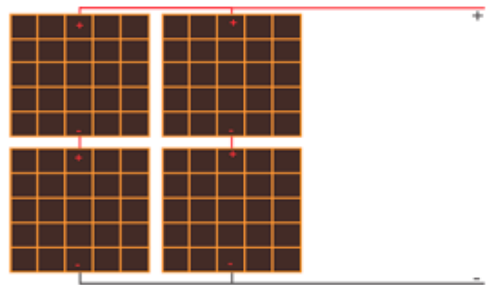

Fig. 11. Association of photovoltaic modules.

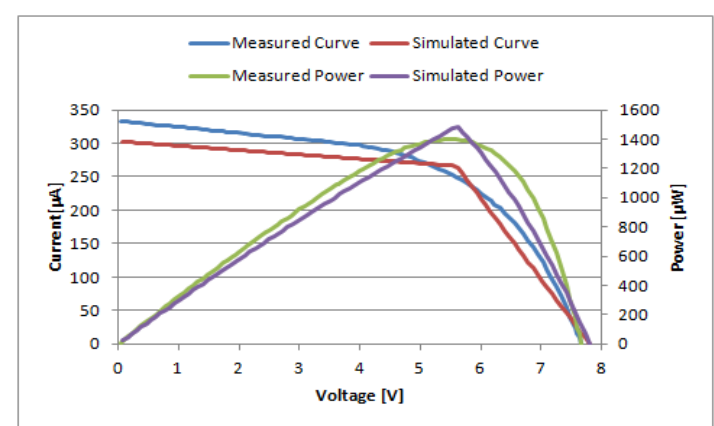

Fig. 12. Power curve simulated/measures, panel under 200 lx.

This number of modules is not sufficient to provide all the energy required by the sensor according to Eq. (5).

$$
\begin{gathered}
E_{\text {module }}=264 \mu \mathrm{A} \times 5.6 \mathrm{~V} \times 28,800 \\
E_{\text {module }}=42.57 \mathrm{~J}
\end{gathered}
$$

It would be necessary to associate a greater number of modules. Another solution found was to carry out the tests under an illuminance greater than 200 lx. In the laboratory, the assays were conducted under illuminance about 697 lx. The panel under the illuminance made the following point of maximum power: $7.01 \mathrm{~V}$ voltage and current of $997 \mathrm{uA}$, Fig. 13.

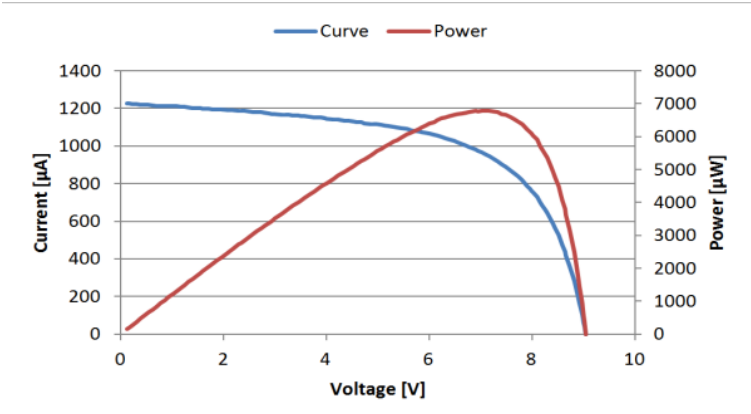

Fig. 13. Electrical characteristics of the panel.

Under these conditions the energy generated by panel for period of 8 hours is $201.28 \mathrm{~J}$, Eq. (6).

$$
\begin{gathered}
E_{\text {module }}=997 \mu \mathrm{A} \times 7.01 \mathrm{~V} \times 28,800 \\
E_{\text {module }}=201.28 \mathrm{~J}
\end{gathered}
$$

The value of capacitance is calculated by the equation of a power capacitor, Eq. (7).

$$
E_{p}=\left(\frac{1}{2}\right) \times \Delta V^{2} \times C
$$

$E_{p}$ - Total storage energy joules [J];

$\Delta V$ - Capacitor voltage variation $[\mathrm{V}]$;

$C$ - Capacitance in Farads $[\mathrm{F}]$.

Eq. (8) is a rearrangement of the capacitor energy equation.

$$
C=\frac{2 \times \mathrm{E}_{\mathrm{p}}}{\Delta V^{2}}
$$

The capacitor should be able to provide $110.07 \mathrm{~J}$ cargo and a voltage of $7 \mathrm{~V}$. In this way the required capacitance value, is presented in Eq. (9).

$$
C=\frac{2 \times E_{p}}{\Delta V^{2}}
$$




$$
\begin{gathered}
C=\frac{2 \times 110,07}{7^{2}} \\
C=4.49 \mathrm{~F}
\end{gathered}
$$

The minimum capacitance value required is $4.49 \mathrm{~F}$. Each supercapacitor have load capacity $1.5 \mathrm{~F}$, and must withstand a voltage up to $9 \mathrm{~V}$, that is the maximum charge voltage. Since, the maximum voltage to the model used is $5.5 \mathrm{~V}$. It is necessary to have a mixed association of supercapacitors to obtain the required values. Fig. 14 shows the association performed with condensers that have $6 \mathrm{~F}$ and supports up to $11 \mathrm{~V}$.

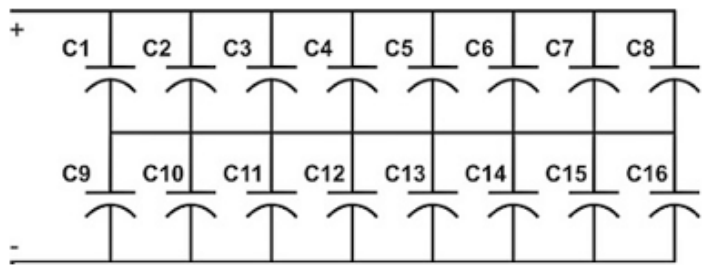

Fig. 14. Supercapacitors association.

\section{EXPERIMENTAL RESULTS}

The test was performed with the panel under illuminance of 704 lux with little variation at measured with the light meter. For the initial mode of the sensor, the measured data are shown in Table VI, these being the initial values of the circuit. The values in this manner does not suffer variation, since the energy consumed is small, Eq. (2).

\begin{tabular}{|c|c|c|c|c|c|c|c|}
\hline Mode & Value & $\begin{array}{c}\mathrm{V}_{\text {PANEL }} \\
{[\mathrm{V}]}\end{array}$ & $\begin{array}{c}\mathrm{V}_{\text {SUP }} \\
{[\mathrm{V}]}\end{array}$ & $\begin{array}{l}\mathrm{I}_{\mathrm{PAN}} \\
{[\mu \mathrm{A}]}\end{array}$ & Ad & $\begin{array}{c}\text { Il } \\
{[\operatorname{lux}]}\end{array}$ & $\begin{array}{c}\mathrm{t} \\
{[\mathrm{s}]}\end{array}$ \\
\hline Initial & Initial & 7.8 & 7.13 & 802 & 0 & 704 & 20 \\
\hline \multirow{2}{*}{ Test } & Initial & 7.8 & 7.13 & 811 & \multirow{2}{*}{59} & \multirow{2}{*}{704} & \multirow{2}{*}{600} \\
\hline & Final & 7.7 & 7 & 847 & & & \\
\hline \multirow{2}{*}{$\begin{array}{c}\text { Normal } \\
\text { (Not added) }\end{array}$} & Initial & 7.71 & 7.04 & 836 & \multirow{2}{*}{0} & \multirow{2}{*}{706} & \multirow{2}{*}{900} \\
\hline & Final & 7.83 & 7.16 & 804 & & & \\
\hline \multirow{2}{*}{$\begin{array}{l}\text { Normal } \\
\text { (added) }\end{array}$} & Initial & 7.83 & 7.16 & 804 & \multirow{2}{*}{5} & \multirow{2}{*}{707} & \multirow{2}{*}{1200} \\
\hline & Final & 7.91 & 7.25 & 789 & & & \\
\hline
\end{tabular}

TABLE VI: SENSOR CONSUMPTION IN LIGHTING TESTS

For the test mode, the energy consumed is larger than the initial mode Eq. (2). For this reason there were variations in the values read. In Table VI, it can be seen that the voltage varied from $7.13 \mathrm{~V}$ (initial) to $7 \mathrm{~V}$ (final). The difference between the panel and the voltage of the supercapacitors, Table VI, is due to voltage drop in the series diode. In the test mode were performed 59 drives, with duration of $6 \mathrm{~s}$ each, totaling $354 \mathrm{~s}$. The energy required was $6.34 \mathrm{~J}$, Eq. (10).

$$
\begin{gathered}
E_{\text {consumed TestMode }}=2.56 \mathrm{~mA} \times 7 \times 354 \\
E_{\text {consumed TestMode }}=6.34 \mathrm{~J}
\end{gathered}
$$

Already the power generated by the panel during the test mode, lasting $600 \mathrm{~s}$, current of $847 \mathrm{uA}$, and voltage of $7 \mathrm{~V}$, is calculated in Eq. (11).

$$
\begin{gathered}
E_{\text {consumedTestMode }}=847 \mu \mathrm{A} \times 7 \times 600 \\
E_{\text {consumedTestMode }}=3.55 \mathrm{~J}
\end{gathered}
$$

Thus, the energy generated by the panel was not sufficient and being necessary the energy supply stored in super capacitors. If the number of sensor shots were as much as possible, 100 drives, the energy provided by super capacitors would be even greater, Eq. (3). The power sensor in the test mode is the largest of the three modes, but for a shorter time

\begin{tabular}{|c|c|c|c|c|}
\hline Mode & Value & $\mathrm{V}_{\text {SUPERCAP }}[\mathrm{V}]$ & Illuminance [lx] & $\mathrm{t}[\mathrm{s}]$ \\
\hline Initial & Initial & 7.13 & 704 & 20 \\
\hline \multirow{2}{*}{ Test } & Initial & 7.13 & \multirow{2}{*}{704} & \multirow{2}{*}{600} \\
\hline & Final & 7 & & \\
\hline \multirow{2}{*}{$\begin{array}{c}\text { Normal } \\
\text { (not added) }\end{array}$} & Initial & 7.04 & \multirow{2}{*}{706} & \multirow{2}{*}{900} \\
\hline & Final & 7.16 & & \\
\hline $\begin{array}{l}\text { Normal } \\
\text { (added) }\end{array}$ & Initial & 7.16 & 707 & 1200 \\
\hline
\end{tabular}
than in the normal mode.

The results of tests performed in the unlit room are in Table VII. The values of illuminance, the voltage and current measured during the tests were zero. Since there was not generation, all energy used was provided by super capacitors.

\section{CONCLUSION}

This work presented the use of thin film photovoltaic modules for power supply of small loads, such as occupancy sensors.

The price of modules is still expensive, and the final cost associated banking and import tariffs make the project with high cost. In the long run, you feel the savings generated by the use of this circuit, but in the short term indicates not be advantageous. If the panels are working at maximum power (MPP), than the charging time could be reduced. Another problem is that the search for that point requires spending and energy data processing. For this, it is necessary a low power consumption device and would need to be able to perform data processing. Otherwise, this device would consume all the energy generated. In the proposed structure, if supercapacitors are already loaded, the excess energy is wasted which reduces the design efficiency.

In turn, the physical space occupied by the system when compared to a battery element that is replaced, is very large. While a battery has measures $4.9 \times 2.6 \mathrm{~cm}$, this project has approximate measures $25 \times 25 \mathrm{~cm}$. However, with the improvement of photovoltaic elements technologies, the size tends to decrease as the efficiency tends to increase.

To be compared to the batteries, the technologies used in this project: photovoltaic modules and supercapacitors, it have a much higher life. With modules with 10 -year warranty manufacturers and supercapacitors with a life span of 30 years, the proposed project is likely to be durable for long time without maintenance, with an option in order to reduce long-term environment and economic impacts.

The results indicate that the use of thin film module technology is technically feasible; however, due to the high cost it is still not economically viable. However, the environmental results obtained from the use of this technology motivate conducting research related to the topic of this work.

\section{ACKNOWLEDGMENT}

The authors thank the company SOLEMS SA for the supply of two photovoltaic modules. Also express their gratitude to FAPESC (Public Call 04/2012 - TO 11340 / 
2012-9) for financial support for the development of the project through LPEE (Electronic Processing Laboratory of Energy). The authors also thank the IFSC and CNPq for financial support to the project through research fellowships and bench help.

\section{REFERENCES}

[1] N. M. V. L. Reidler and W. M. R. Gunther, "Waste management consisting of cells and batteries," in Proc. 27th Interamerican Congress of Sanitary and Environmental Engineering, Porto Alegre, 2000.

[2] R. Sing, G. F. Alapatt, and A. Lakhatakia, "Making solar cells a reality in every home: Opportunities and challenges for photovoltaic device design," IEEE Journal of the Electron Devices Society, vol. 1, no. 6, June 2013.

[3] A. Ghensev, "Materials and manufacturing processes of photovoltaic cells," Final study report, Federal University Lavras, 2006.

[4] K. Agroui, A. H. Arab, M. Pellegrion, F. Giovanni, and I. H. Mahammad, "indoor and outdoor photovoltaic module performance based on thin films solar cells," Revue des Energies Renouvelables, vol. 14, no. 3, pp. 469-480. 2011.

[5] S. C. Gau, "Characterizations and analyses of large-area

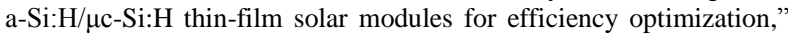
IEEE Journal of Photovoltaics, vol. 3, no. 1, January 2013.

[6] A. Schneuwly and R. Gallay, "Properties and applications of supercapacitors from the state-of-the-art to future trends," in Proc. Power Conversion Intelligent Motion Conference, Boston, 2000.

[7] N. Javanmard, G. Vafadar, and A. Nasiri, "Indoor power harvesting using photovoltaic cells for low power applications," IEEE Transactions on Industrial Electronics, vol. 56, 2009.

[8] M. E. Glavin, P. K. W. Chan, and W. G. Hurley, "Optimization of autonomous hybrid energy storage system for photovoltaic applications," in Proc. IEEE Energy Conversion Congress and Exposition, 2009, pp. 1417-1424.

[9] M. Konagai, "Current status of thin-film solar cells and future prospects," in Proc. 2013 Twentieth International Workshop on Active-Matrix Flatpanel Displays and Devices (AM-FPD), 2013, Kyoto, Japain.

[10] H. E. Oliveira, "Photovoltaic technology in thin films (thin film)," Final study report, Federal University of Lavras, 2008.

[11] L. M. P. Fanjul, "Some new applications of supercapacitors in power electronic systems," Master thesis, Texas A\&M University, 2003.

[12] N. C. Braga. Ultracapacitores (ART244). [Online]. Available: http://www.newtoncbraga.com.br/index.php/como-funciona/1663-ultr acapacitores
[13] D. Campos, "Proposed use of photovoltaic cells for indoor feeding remote electronic loads," Final studies report, Federal Institute of Santa Catarina, Florianópolis, 2013.

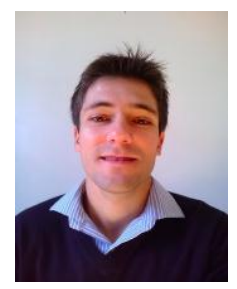

Dyego de Campos was a technologist in electronic systems at the Federal Institute for Education, Science and Technology of Santa Catarina in 2013. He is currently a technician with the Electronics Department, Federal Institute for Education, Science and Technology of Santa Catarina, Florianópolis. His areas of interest are photovoltaic system, renewable energies, and power electronics.

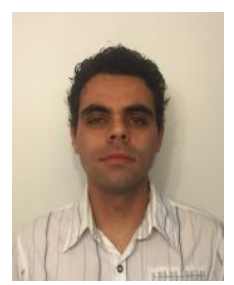

Bryan D. Pinheiro is a student of the technologist in electronic systems curse at the Federal Institute for Education, Science and Technology of Santa Catarina. His areas of interest are photovoltaic system, renewable energies, and power electronics.

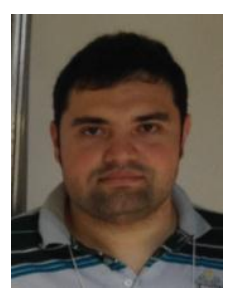

Diego L. da Silva is a student of the technologist in electronic systems curse at the Federal Institute for Education, Science and Technology of Santa Catarina. His areas of interest are photovoltaic system, renewable energies, and power electronics.

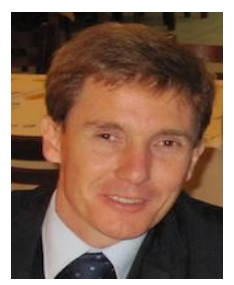

Clovis A. Petry was born in São Miguel do Oeste, Santa Catarina, Brazil, in 1972. He received the B.S. degree in electrical engineering and the M.S. and Ph.D. degrees from the Federal University of Santa Catarina, Florianópolis, Brazil, in 1999, 2001, and 2005, respectively.

$\mathrm{He}$ is currently a professor with the Electronics Department, Federal Institute for Education, Science and Technology of Santa Catarina, Florianópolis. His areas of interest are ac-ac converters, line conditioners, and control of those converters. 